\title{
International policy, development expertise, and anthropology
}

\author{
David Mosse
}

This forum article has two parts. In the first, I make some observations about policy knowledge in international development and the ways in which it has become the subject of anthropological study. In the second, I reflect on the relationship between anthropological knowledge and the development world that it describes, asking, "what's the use of anthropology to international development?"1

\section{The study of policy knowledge in international development}

The comforting belief that the problems of widespread and extreme poverty in the world will be solved through the riches of global capitalism is pervasive. The major development agencies that have made poverty reduction the goal of development have also made economic growth its means. The problem is that this obscures and simplifies the relationship between the two, ignoring the various ways in which the relations of capitalism also create poverty (Harriss-White 2006), for instance, through the "adverse incorporation" of exploited groups such as tribal (adivasi) migrant laborers who today work under highly exploitative conditions in the construction sites and laying telecommunication cables for the rapidly expanding industrial growth poles of western India (Mosse 2007). Indeed, broadly, the idea of globalization itself tends to overlook the political economy of capitalism as a system of power, just as trust in the regimes of global governance designed to regulate flows of capital, goods, and labor overlooks the ways in which the regulations involved in-build the interests of the most powerful players (Mosse 2005 and references cited, e.g., Fine 2004).

For the most part, aid agencies have little to say about such matters of global power and impoverishment. Instead, they make a great deal of the power of ideas, right theory, or good policy in solving problems of global poverty. Anthropologists trying to understand development rightly pay attention to its discourses but still need to take a closer look at the actual knowledge practices of the experts and professionals who constitute the field of international development. Not only is extraordinary power given to ideas these days, but there is also unprecedented expert consensus on how global poverty is to be eliminated and the poor are to be governed, brought about by new processes of aid 'harmonization' or 'alignment.' At the same time, an emphasis on partnership, consultation, local ownership, transparency, and publicity set the ideological conditions for aid such that in a postproject, postprogram era, aid agencies stress that they no longer intervene but merely support the conditions under which nationally directed poverty reduction can happen.

At the center of the intellectual consensus is a marrying of orthodox neoliberalism and new 
institutionalism, the latter being the notion that poverty and violence are the result of bad governance and what is needed are stronger institutions, for example, for the delivery of services accountable to the poor. Of course, this is no return to state provision but rather a matter of giving resources to governments to make markets work so as to reduce poverty; or as Craig and Porter put it, disaggregating and marketizing the state- -that is, breaking up existing forms of state rule (dismissed as corrupt or patrimonial) and then "using markets to replace and reconstruct the institutions of governance" (2006: $9,100)$, while at the same time re-embedding markets in regulatory and constitutional frameworks.

The policy models involved here are highly formalistic, framed by the universal logic of new institutional economics (rules/incentives) and of law (rights/accountability). They are "travelling rationalities" with general applicability in which, as Craig and Porter note, "the universal [is asserted] over the particular, the travelled over the placed, the technical over the political, and the formal over the substantive" (2006: 120). These authors also point to the "vertical disaggregation" of policy making: on the one hand, a delegation upward of rule making and policy framing from poor country governments to the global stage, to international agencies, private organizations, NGOs, or companies (centralization plus formalism allowing economics to retain its preeminence as the diagnostic and rulemaking discipline of "Aidland"; see Woods 2006: 66ff); on the other hand, a neoliberal delegation downward to 'responsibilized' regions, localities, and ultimately individuals that extends formal modeling from national economies to the intimate spaces of communities. Through participation in expert designs citizens themselves become expert at disembedding and recombining elements of their own institutions or socioecologies, and acquire a new technical (disembedded) view of themselves and of processes of social change in terms of modified rules, accountability mechanisms, and structures of incentives-in short, "getting social relations right” (Woolcock 1998). Here social science (in- cluding ethnography) is deployed "to render society technical," as Tania Li (2007) puts it; that is, conceived in terms of calculative rationality, self-organization, or the deficits/surpluses of social capital, so as to allow expert-designed interventions.

The point here is not only that donor-established liberal frameworks of governance pull "a thin institutionalist veil over fundamental (often territorial) aspects of poverty," maintaining the formalist "delusion that agency can be incentivized to operate independently of political economy" (Craig and Porter 2006: 11, 27, 120), but also that this delusion is required, indeed actively maintained, by aid systems that have the political need to explain how social and governmental orders can be reorganized by international policy and aid. The structures of representation that define the accepted interpretation of what is going on and what can be accomplished (currently neoliberal institutionalist ones) have to be kept in place. And to this end experts (including anthropologists) are needed in order to dissembed theory from practice discursively so as to preserve a sphere of rational intention that can appear as external to and generative of events, so as to, as Mitchell puts it, "rearrange power over people as power over ideas" (2002: 90). Whatever the specific or current policy goals, the aid system has the core system goal of maintaining the power of ideas. Its knowledge practices-including the succession of meetings, conferences, conventions (Rome, Paris, Accra) around which agencies order and map their activities-affirm the power of ideas and the status of 'thought work' and 'knowledge banks' in the world system, as well as secure the global 'knowledge ways' through which senior people can travel from meeting to meeting. The very instability of any particular policy consensus, the constant rethinking, rerationalizing, and wrong-footing of those who have last year's ideas ('"governance'-that's so 2007 !") keeps the show on the road. ${ }^{3}$

Here anthropology's business is to focus on the social relations underpinning thought work; to show how development's traveling rationalities are never free from social contexts, how they 
begin in social relations, in institutions and expert communities, travel with undisclosed baggage, get unraveled as they are unpacked into other social/institutional worlds-perhaps through the interests of local collaborators, official counterparts, or brokers-and are recolonized by politics in ways that generate complex and unintended effects.

Anthropologists are skilled at demonstrating that, as Mitchell argues, the effects of aid interventions do not come from the imposition of preformed designs from outside, nor from their own logic, but are brought about through the changes they effect in existing cultural, political, and ecological systems (2002: 77). But they also look at the social-institutional processes that are necessary for maintaining trust in experts and belief in the significance of policy models and aid flows. These include the denial of history, or as Pritchett and Woolcock (2004) put it, the practice of "skipping straight to Weber," that is, transferring from place to place principles of bureaucratic rationality, which carry with them institutional mythologies that conceal the fact that in reality institutional solutions "emerge from an internal historical process of trial and error, and of political struggle," and that part of "the solution" is to hide this fact (ibid.: 201).

So while anthropologists of development have conventionally concerned themselves with describing the relationships, events, and politics that development expertise conceals, many now turn to examining the social mechanisms through which aid programs create or sustain the expertise that legitimizes or governs them. They do so in rather different ways. Some take their cue from work on the political economy of knowledge, examining the knowledge processes of development organizations in terms of the interlinking of expert knowledge, institutional power, and organizational legitimacy in agencies such as the World Bank (e.g., Goldman 2005).

Other anthropologists turn ethnographic attention to extrainstitutional or transnational networks of experts through which policy is shaped, for example, Janine Wedel's (2000) work on the U.S. economic aid program to Russia and her striking account of crony relationships between expert players from Harvard and their Russian partners in the so-called Chubais Clan. Yet others examine the transmission mechanisms of expert knowledge, especially those internal to organizations, that reveal the everyday practices of professionalization, ideological control, and inheritance, the self-disciplining structures of incentives, say, within aid agency career building, that give resilience to expert ideas at the center in face of contrary evidence; the 'group think,' censorship, and reliance on templates that (Woods 2006 argues) minimize individual risk by dispersing accountability and blame (in case of failure) to the institution as a whole; and today more widely since the interlinking of the orthodoxies of different international aid organizations lends further stability to established models (Eyben, forthcoming). Meanwhile, project evaluation systems are organized so as to distribute events on either side of a divide between the intended and the contingent so as to produce paradigm success out of program failure.

Other ethnographic work suggests that the resilience of international development's key ideas comes not only from structural power or selfdiscipline but also from the function that ideas have within aid agencies. Here anthropologists treat knowledge production as a micropolitical field, examining the social life of ideas. For example, from this view, the World Bank's now much criticized idea of social capital would be regarded not as demonstrating the power of the Bank to depoliticize development (the common criticism) but as the outcome of tactical concessions by a vulnerable group of social scientists to economics paradigms, a (globally exported) survival strategy within a mega-organization (Mosse, forthcoming). Then ethnographers such as Annelise Riles (2001) conduct ethnography on and through the analytical forms of expert ideas themselves, their effects, the precedence of form over content, style over substance, their production of forms of sociality as in 'the network.'

Finally, in their ethnographic pursuit of the social context of development's traveling rationalities, anthropologists turn attention to the social lives of international experts and development professionals (perhaps even ourselves). 
Harmonized or homogenized development thinking (and the denial of local context) has its basis in the sociality of international communities of experts-locally transient but internationally permanent (Eyben, forthcoming). These are well knit through employment circuits and electronic communication and, as Jonathan Friedman points out, closed in class terms and "top-lifted" from representative democracy: highly visible in the capital cities of the developing world, occupying cultural enclaves, shared lifestyles and values - a group that despite cosmopolitan claims, is "at least as restricted as any other strong ethnic identity” (2004: 167).

There may be something in the idea that for international experts, social and intellectual closure is a weapon against uncertainty and unmanageable contexts, as well as the risk of failure; but the real dilemma for such professionals (the agency staff, NGO managers, or project workers and consultants I have worked with) is that they do have to engage in the messy, emotion-laden practical work of negotiating presence within national bureaucracies, compromise, rule bending, and meeting targets and spending budgets, not to mention personal security, loneliness, family relations, and stress. And yet they have to make themselves bearers of context-free "traveling rationalities" and transferable skillswhether in the realms of health-sector reform, plant science, economic analysis, or "people's empowerment." From this come cosmopolitan and technocratic claims. Professionalism (career building) requires recovering the universal from the particular, technocratic knowledge from the illicit relationships upon which it is actually based conceding what is known from experience to the simple instrumentality of the models of employers, bosses, or supporters (Riles 2004). For different reasons, both the World Bank's investors and borrowers and the charitable donors to Oxfam require the "illusion of certainty” from their experts (Woods 2006).

Of course, development professionals are by no means ignorant of the fact that their formal models (or technologies) are political in conception and slippery in application, as Craig and
Porter (2006) put it. Indeed, the challenge of turning the political into the technical is not so easily handled. Professional identities are themselves fragile. And the reflexivity this generates among people well aware of their dilemma is evident in the ubiquitous backstage skepticism, irony, self-criticism, spoof, and humor that is part of professional groups, whose members may self-marginalize from their own power, distancing themselves from the naïveté of the zealous, as Annelise Riles $(2004,2006)$ points out, referring to human rights lawyers; the true professional is a bit cynical. Occasionally professionals offer personal accounts of the real micropolitics of their expertise found in books by development economists, aid workers, NGO staff, or diplomats. These unofficial subversive accounts of insider experts, Holmes and Marcus (2005) suggest, are a para-ethnographic counterpart to anthropologists' writing. How, then, do anthropologists position their knowledge in relation to a world of policy rationality and development practice that is also reflexive?

\section{Anthropological knowledge and the development world}

It has become a convention that the space for knowledge that is anthropological falls outside of the realm of policy and program practice. The anthropological starting point is skepticism regarding the claims of international development agencies to improve the conditions of "other people." Indeed, it is fashionable to assert that claims to improve actually disguise governmental ambitions (national or international) to discipline, control, and incorporate "dangerous borderlands" into global capitalism. And if not actually hostile to involvement in programmatic advisory work for agencies, some anthropologists argue, as Tania Li does in her book The Will to Improve, that "the positions of critic and programmer are properly distinct," that "an ethnographic appreciation of the complexities of rural relations [is] antithetical to the position of expert," and that a "bridge between research on the 
dynamics of social life and the world of projects" that experts inhabit eludes her (2007: 2-3).

Now, the distinction that Li draws between programming and social life is mistaken in that the dynamics of social life include the world of projects (agencies, fieldworker reporting, policy making, etc.), but it is correct in that what is required of actors within programming worldsas professionals-is precisely that they disembed their understandings and identities from this social world. In other words, the distinction itself is a product of institutional work. Anthropologists' contribution is not to reassert the division between social and programming worlds but to examine it especially through occupying that unstable crossing between development institutions and the world they seek to change.

I do think there is a need to reassess and rehabilitate the contribution of anthropology to development, but not as an expert field-say, in relation to indigenous knowledge or participatory approaches; not as the task of building social knowledge into policy prescriptions, promoting a localist stance, or even cultural brokerage-but as a way of reflecting on the wider social and cultural context of development, of aid recipients, programs and policy making itself, critically engaging with the "dilemmas of power and knowledge that shape the aid system" (Eyben, n.d.). The task is neither to make planning knowledge out of ethnography (the programming demand) nor to make ethnographic knowledge out of normative planning (the critical demand). Rather, it is to create space within programming worlds for anthropology's interpretive description-that takes social relations, everyday interactions, and divergent meanings seriously-and to regard this description as a vital source of insight, learning, and adaptation. As in any anthropological practice, insight comes from combining the experience of insider participation with the detachment of an outsider, the ability to stand outside the taken-for-granted frameworks and to see the arena of international development as a foreign country-the social life and cultural practice of what Raymond Apthorpe (forthcoming) has called "Aidland"- asking as one would of any unfamiliar culture not whether but how it works.

What anthropology offers, then, is not just research knowledge on development problems, new policy recommendations, or a better tracking of results but awareness of the very uncertain link between intention and outcome, as well as a better understanding within development agencies of how they think and what their action does. In other words, anthropology can open up or build on a reflexive capability that is especially necessary in international aid organizations (Eyben, n.d.).

However, there is a problem. Anthropologists have had a tendency to use description to deconstruct or detract from development, perhaps substituting power effects for stated motivations; practitioners have a tendency to regard any description as an evaluation. The encounter is fraught with distrust. Is it possible for anthropologists of development to desist from explaining away the reality of programs and instead, in Bruno Latour's terms (2004), "strengthen their claim to reality" by tracing policies, project designs, or technologies back to the human relationships, the "gatherings" from which they come and that they contain; to see that policy constructions and professional identities are fragile, perhaps in need of protection?

Can programmers learn that description is not evaluation? Here the real problem with anthropology is not that it is inherently critical of development interventions but that its field of inquiry — events, context, informal relationships, divergent views, and the effects of power-links it with narratives of program failure. Attention to the ordinarily suppressed relations and processes - those things of ethnographic interestusually appears only in the context of failure and its narratives of blame. The culture of Aidland brings a distinctive asymmetry to the treatment of success and failure. While success buries the individual action or event and directs attention to the transcendent agency of policy ideas, expert design, or technology (and hence replicability), failure fragments into the dynamics of blame (Latour 1996: 76). While development 
narratives of success are theory-rich, those of failure are inherently event-rich.

There is a deep antipathy between the work of professional identity formation, which requires disembedding policy theory from complex relations and events, and the ethnographic project of unpacking program models into social relations. The analysis through which an anthropologist generates fresh knowledge and fulfills his or her professional identity is the same that might unravel the expertise and professionalism of others-something that struck me in the reception of my own ethnography of aid policy and practice (see Mosse 2006). A controversy that was generated around divergent epistemologies and ethnographic description unruled by authorized interpretations acquired edge in the claim that damage had been done to professional reputations by an insider colleague turned ethnographer. Confrontations of this sort are not so rare. Aid organizations are no more willing than others to expose their internal workings or external representations to scrutiny, and are ready to invoke threats (budget cuts, harm to poor beneficiaries) to justify secrecy (Eyben, n.d.).

The fact is, research founded on the paraethnographic - the "marginal social thought" of insider practitioners (Holmes and Marcus 2005) - is not so easy to pull off in practice. It is strikingly hard for professionals within development organizations (state or NGO) to develop their reflexive insights on relationships, events, and meaning beyond official space, in explicit, written, and discussible form. While evidently organizations have limited capacity to shape individual thought, overt skepticism is suppressed and the development (and publication) of critical para-ethnographic perspectives has typically been linked to (or led to) organizational exit.

But perhaps in the end such direct contests are less important than the systematic elimination of ethnographic perspectives by the manner in which social science is today institutionalized within major donor agencies. There is a very real tension (if not a direct contradiction) between the knowledge and critical insights that anthropologists can offer and the manner in which the discipline is currently institutionalized within international development agencies. Indeed, as the numbers of social scientists have increased in aid organizations, ethnographic competence has probably declined. For one thing, in the World Bank and other agencies, social science thinking has been strongly shaped by the need to define and defend the professional space of this vulnerable group within economics-dominated organizations. It is certainly true that anthropologists have used exemplar programs on the periphery (within certain country contexts) to make strategic choices, change aid management rules, and stimulate demand for social expertise. But here anthropological knowledge gains authority less from its capacity to describe or interpret social structure or power relations than from its capacity to "render society technical" (Li 2007). But at the organizational centers, anthropologists are marginalized: obviously by economics-based frameworks (and career paths) but also (at the World Bank) by their initial concern with the prevention of harm (with obstaclegenerating safeguards, operational directives on involuntary resettlement or on indigenous people, etc.). In consequence, the center of social science conceptual work has gravitated toward instrumental formulations of 'the social' in order to frame 'social development' objectives within core neoliberal policy dialogue, which (especially in the Bank) can be sold internally or to other donors as 'social analysis' productsbusiness lines, 'off-the-shelf' packages of concepts, models, best practices, tools, and how-to materials. In the Bank these function as 'corporate products' useful for the internal negotiation of loans and projects, but with limited influence either on operations or in research. Nonetheless, they contribute to a knowledge system that perpetuates the separation of the world of policy rationality from the contradictions of donor practice (Mosse, forthcoming).

It remains to be seen whether growing awareness (on the fringe) of what is at stake in suppressing the critical insight of insiders or institutionalizing social science within knowledge systems that contribute to internal legitimizing while organizing attention away from the com- 
plex relationships of practice, power, and the plurality of perspectives can shift this arrangement. It would seem perverse to deny that anthropological approaches can help those in international development agencies acquire a better understanding of themselves and the context of their thought and action-but certainly not through ignoring the necessary tension between the work of programming and that of description, nor through deconstructive analysis that isolates criticism from policy and practice.

Where anthropology's insights come from, and what its ethnographic method requires, is a crossing and recrossing of the boundary between the insider operational and the outsider researcher positions. The challenge for development organizations is to relax the 'border controls' of Aidland so as to allow their professionals to exit into reflexive awareness of their own ways of knowing and acting, to acquire critical descriptive capabilities, and to reenter with discussible findings beyond the genre of effectiveness and best practice. The challenge for anthropologists of development is to find constructive modes of reentry for engagement with the goals of development; to find a way to be interactive and contribute to public knowledge regimes, fully recognizing that this is a highly political space, in which anthropological knowledge has to negotiate its place, without being instrumentalized, rejected outright, or unraveled through mechanisms of consensus.

David Mosse is professor of social anthropology at the School of Oriental and African Studies, University of London. He is author/editor of several books on development, including Cultivating development: An ethnography of aid policy and practice (2005). His most recent edited collection is Traveling rationalities: The anthropology of expert knowledge and professionals in international development, forthcoming from Berghahn Books.

E-mail:dm21@soas.ac.uk.

Mailing address: Department of Anthropology, School of Oriental and African Studies, Russell Square, London, WC1 HOXG.

\section{Notes}

1. Some passages of this piece draw from the text of public lectures with this title that I gave in November 2007 at the Universities of Guelph and Simon Fraser, Vancouver (the Canadian International Development Research Centre supported 2007 Hopper Lecture), and in revised form as an inaugural lecture at SOAS (18 January 2008).

2. To coin Raymond Apthorpe's (forthcoming) term.

3. Themes aired at the recent Norface conference on the knowledge practices of international development agencies, Helsinki, Finland, May 2008.

\section{References}

Apthorpe, Raymond, forthcoming. Alice in Aidland. In Traveling rationalities: The anthropology of expert knowledge and professionals in international development, ed. David Mosse. Oxford: Berghahn.

Craig, David, and Doug Porter. 2006. Development beyond neoliberalism: Governance, poverty reduction and political economy. London: Routledge.

Eyben, Rosalind. n.d. Hovering on the threshold: Challenges and opportunities for critical and reflexive ethnographic research in support of international aid practice. Unpublished paper.

- Forthcoming. The sociality of international aid and policy convergence. In Traveling rationalities: The anthropology of expert knowledge and professionals in international development, ed. David Mosse. Oxford: Berghahn.

Fine, Ben. (2004) Globalization or panglossianization? A critical response to Keith Griffin. Development and Change 35 (3): 583-91.

Goldman, Michael. 2005. Imperial nature: The World Bank and struggles for social justice in the age of globalisation. New Haven, CT: Yale University Press.

Harriss-White, Barbara. 2006. Poverty and capitalism. Economic and Political Weekly, 1 April, 1241-46.

Holmes, Douglas R., and George E. Marcus. 2005. Cultures of expertise and the management of globalisation: Towards a re-functioning of ethnography. In Global assemblages: Technology, politics and ethics as anthropological problems, ed. Aihwa Ong and Stephen Collier, 235-52. Oxford: Blackwell. 
Latour, Bruno. 1996. Aramis, or the love of technology, trans. Catherine Porter. Cambridge, MA: Harvard University Press.

- 2004. Why has critique run out of steam? From matters of fact to matters of concern. Critical Inquiry 30 (Winter 2004): 225-48.

Li, Tania Murray. 2007. The Will to improve: Governmentality, development, and the practice of politics. Durham, NC: Duke University Press.

Mitchell, Timothy. 2002. Rule of experts: Egypt, techno-politics, modernity. Berkeley: University of California Press.

Mosse, David. 2005. Global governance and the ethnography of international aid. In The aid effect: Giving and governing in international development, ed. David Mosse and David. Lewis, 1-36. London: Pluto Press.

. 2006. Anti-social anthropology? Objectivity, objection and the ethnography of public policy and professional communities. Journal of the Royal Anthropological Institute 12 (4): 935-56. - 2007. Power and the durability of poverty: A critical exploration of the links between culture, marginality, and chronic poverty. CPRC Working Paper No. 107, December 2007. Available at http://www.chronicpoverty.org. -. Forthcoming. Social analysis as corporate product: Non-Economists/anthropologists at work in the World Bank in Washington DC. In Travelling rationalities: The anthropology of expert knowledge and professionals in international development, ed. David Mosse. Oxford: Berghahn.

Pritchett, Lant, and Michael Woolcock. 2004. Solutions when the solution is the problem: Arraying the disarray in development. World Development 32 (2): 191-212.

Riles, Annelise. 2001. The network inside out. Ann Arbor: University of Michigan Press.

- 2004. Real time: Unwinding technocratic and anthropological knowledge. American Ethnologist 31 (3): 392-405.

- 2006. Anthropology, human rights, and legal knowledge: Culture in the iron cage. American Anthropologist 108 (1): 52-65.

Wedel, Janine. 2000. Collision and collusion: The strange case of Western aid to Eastern Europe. New York: Palgrave; Basingstoke, UK: Macmillan.

Woods, Ngaire. 2006. The globalizers: The IMF, the World Bank and their borrowers. Ithaca, NY: Cornell University Press.

Woolcock, Michael. 1998. Social capital and economic development: Towards a theoretical synthesis and policy framework. Theory and Society 27: 151-208. 